\title{
LA IMPORTANCIA DEL LENGUAJE Y EL APRENDIZAJE EN EL DESARROLLO DEL NIÑO
}

\author{
Raquel Calderón Coronado
}

\begin{abstract}
RESUMEN
El lenguaje es uno de los aspectos fundamentales en el desarrollo del niño, es el arma maravillosa que abre miles de puertas a otros conocimientos, es la herramienta de relación con otros y permite interaccionar adecuadamente. El primer lugar donde ha de desarrollarse este lenguaje será en el seno familiar, en las primeras interacciones con la madre, en aquellos primeros balbuceos y que paulatinamente va desarrollándose; a su vez, con su ingreso a la escuela evoluciona cada vez más hasta alcanzar su máximo desarrollo. Es por tanto, labor fundamental de las familias, de los padres, procurar desarrollarlo e identificar las dificultades que puedan presentar sus bebés para acudir a un especialista cuanto antes. Por otro lado, están los profesores de Educación Inicial quienes no solo deben estar atentos a las dificultades que puedan presentar sus alumnos, sino que deben buscar desarrollar al máximo sus potencialidades verbales.
\end{abstract}

PALABRAS CLAVE

Lenguaje, escuela, desarrollo del lenguaje, estimulación de lenguaje, problemas de lenguaje.

\section{ABSTRACT}

Language is one of the fundamental aspects in the development of the child, it is the wonderful soul that opens thousands of doors to other knowledge, is the tool of relation with others and allows properly interacting. The first place where this language has to develop will be in the family, in the first interactions with the mother, in those first babbling and that gradually develops, at the same time, with its entrance to the school evolves more and more until reaching its maximum development. It is therefore the fundamental task of families, parents to try to develop it and to identify the difficulties that their babies can present to go to a specialist as soon as possible. On the other hand, Early Education teachers not only must be attentive to the difficulties that their students may present, but must seek to develop their verbal potential as much as possible.

KEYWORDS

Language, school, language development, language stimulation, language problems.
$\mathrm{H}$ oy en día, cada vez más aumentan los problemas de lenguaje y aprendizaje en niños, lo cual lleva a darse cuenta cuán importante es tanto el lenguaje como el aprendizaje en el desarrollo de un niño. Uno de los aprendizajes más importantes que los niños adquieren en sus primeros años de vida es su lengua materna, siendo sus padres y hermanos, los primeros modeladores de su lenguaje; son sus primeras relaciones en el ambiente familiar donde surgen las primeras interacciones, los intercambios comunicativos, sentándose así las bases de futuros y más complejos aprendizajes (J. L. Gallego 2003).

Actualmente, se está tomando conciencia que cada vez aumentan más las familias disfuncionales, los hogares donde ambos padres trabajan todo el día y los hijos se quedan a cargo solo de las cuidadoras, que solamente se encargan de la tareas domésticas dejándolos en la más amplia libertad y sin guía al desarrollo del niño; por otro lado, están las escuelas, que les cuesta asumir que el lenguaje es, sin duda, el instrumento de comunicación y de representación por excelencia, un medio fundamental para el desarrollo personal, social de un niño, el recurso más poderoso y eficaz para la adquisición de los aprendizajes escolares. Es aquí donde entran a tallar los maestros, quienes son los encargados de detectar los problemas de lenguaje, pero su labor no consiste únicamente en derivarlos a centros especializados, deben ser maestros que orienten, guíen, desarrollen estrategias de lenguaje y aprendizaje facilitadores para un óptimo desarrollo del niño. 
Por tanto, debemos tratarlo con la máxima dedicación, remitiendo cualquier situación anómala en la evolución lingüística de los niños a la atención de los especialistas. El papel del especialista comprende diversas funciones, a nivel preventivo en cuanto puede compensar aquellas dificultades que aparezcan, siendo en este sentido de vital importancia, el detectar, evaluar, diagnosticar, tratar y orientar problemas o déficits para evitar que pasen a mayores, dado que por lo general, todo problema de lenguaje no resuelto en la infancia, termina convirtiéndose en un problema de aprendizaje posterior.

\section{Ellenguaje hoy en día}

El lenguaje, actualmente es una capacidad por excelencia de todo ser humano, aquel que distingue al ser humano de los animales, aquel que abre puerta a un sinfín de conocimientos. Bajo este enfoque, el desarrollo del lenguaje oral es un aspecto fundamental en el desarrollo de todo niño, ya que cumple una función no solamente de comunicación, sino también de socialización, humanización y autocontrol de la propia conducta. El desarrollo evolutivo del lenguaje en el niño comienza a desarrollarse desde que nace, ya que en los primeros meses de vida, empieza con las llamadas vocalizaciones que van desde el primer al tercer mes, luego la consonantización que va desde el tercer al sexto mes y las silabaciones van desde el sexto al noveno mes. Todas estas emisiones son de tipo reflejas. Es aquí donde las madres al interactuar con sus hijos, esbozan las primeras y largas conversaciones que tendrá el niño en su vida, en estas primeras interacciones los bebés aprenden patrones, modelos de lenguaje, gestos, tonos que se van desarrollando poco a poco. No obstante, ante esta reflexión surgen preguntas: ¿Qué pasa con aquellos niños que no interrelacionan con sus madres, porque estas salen a trabajar? ¿Qué sucede con aquellos niños que pasan horas frente a un computador o televisor y no logran desarrollar esas largas conversaciones con sus madres?, ¿Qué hay con aquellos niños que se encuentran al cuidado de terceros, quienes solo los tienen postrados en un corral o en un coche sin mayor estimulo verbal? Sin duda son los candidatos a presentar dificultades de lenguaje o de aprendizaje en un futuro cercano, por ello, nuevamente se cae en la importancia del lenguaje desde el seno materno, donde se debe procurar estimularlos al máximo, enriquecer sus conversaciones, dirigir sus aprendizajes, acompañarlos, guiarlos y buscar ante todo interactuar con ellos, evitando así los monólogos o mutismo ante un computador.

2. Una rápida mirada a la evolución del lenguaje

La evolución del lenguaje está relacionada con el desarrollo cognitivo y socioafectivo. En un principio va acompañado de gestos y mímicas que van desapareciendo a medida que este se desarrolla. Por ello, conviene conocer las fases dellenguaje:

\section{La fase pre lingüística}

Esta fase corresponde a la fase de la inteligencia sensorio motriz, la cual se da durante el primer año de vida, se caracteriza por la práctica de ejercicios fonéticos, balbuceos y vocalizaciones que en un principio se utilizan por puro placer motor. El niño juega con sus órganos de fonación, con sensaciones musculares vibratorias y auditivas, comenzando con llantos, risas, gritos, ruidos que se dan cuando come, succiona. A medida que va desarrollándose, hacia los diez meses, las vocalizaciones son más cortas y van apareciendo las primeras producciones intencionales.

\section{Lafase lingüística}

Esta fase se inicia a partir del año y se caracteriza por la utilización del lenguaje propiamente dicho. En esta fase el 
desarrollo del lenguaje se dará en cuatro niveles, conocidas como las dimensiones o áreas dellenguaje.

* Elnivel fonético-fonológico: emisión de los s o n id os o fon emas y perfeccionamiento de los mismos.

* El nivel semántico: adquisición de vocabulario expresivo y comprensivo.

* El nivel morfosintáctico: elaboración de frases.

* Elnivel pragmático: uso del lenguaje en la vida diaria.

3. Lasfunciones dellenguaje

El lenguaje, tal como se ha mencionado anteriormente, es de vital importancia para el desarrollo del niño, dado que tiene funciones esenciales en su desarrollo evolutivo. Las funciones del lenguaje son los instrumentos de comunicación que insertan al niño en su entorno social y cultural, favoreciendo y regulando sus procesos mentales. Karl Bühler, pedagogo, psicólogo y lingüista alemán, propuso tres únicas funciones:

La función representativa o referencial, se encarga de transmitir una información objetivamente, donde el hablante informa sobre determinada realidad.

La función emotiva o expresiva, es la que utiliza el emisor para expresar sentimientos.

La función conativa o apelativa, el emisor espera el inicio de una reacción por parte del receptor.

\section{La importancia dellenguaje oral}

El lenguaje es un intercambio de información a través de un determinado sistema de codificación, donde los sonidos se articulan en palabras y estas en frases que tienen un significado y es lo que se quiere transmitir. Siendo el lenguaje oral un proceso complejo, que implica un código de símbolos, la adquisición de vocabulario o la elaboración de frases, todo ello, conlleva a tener una serie de capacidades, que resultan ser las condiciones básicas para que se pueda desarrollar, como: la maduración del sistema nervioso, un adecuado aparato fonador, un nivel suficiente de audición, un grado de inteligencia mínimo, una evolución psicoactiva, una estimulación del medio y relación interpersonal. Los resultados de muchas investigaciones demuestran que el lenguaje influye en la memoria y en la percepción, ya que ayuda a hacer generalizaciones, a asociar, diferenciar los rasgos más significativos de las cosas y permite la acumulación de recuerdos e información, por ello que la conducta humana está basada en el lenguaje oral, el cual contribuye a la organización del comportamiento del niño, al conocimiento de las propias sensaciones y sentimientos, llegando a ser un elemento de autocontrol y modificación de la propia conducta.

5. Ellenguaje como proceso de socialización

Muchas de las funciones consideradas como intrapersonales, es decir, desarrollo del lenguaje, desarrollo simbólico, resolución de problemas, formación de conceptos, atención y memoria, se originan en un contexto interpersonal ya enunciado por Vigotsky, quien afirmaba que en el desarrollo del niño toda función aparece dos veces: primero en el plano social y luego en el plano individual; lo cual significa que primero se da entre personas y después en el interior del propio niño. Esta doble aparición tiene su reflejo en el papel que juega, lo que este autor ha denominado "zona de desarrollo próximo", refiriéndose a la situación que se produce en una interacción. El papel de la zona de desarrollo próximo es 
fundamental para entender cómo se produce el desarrollo del lenguaje en el niño y el papel activador que con su actuación ejerce el adulto.

Es en este sentido, que los niños necesitan estimulación para iniciarse en el aprendizaje de la lengua, donde el ambiente familiar supone el principal estímulo para la adquisición del lenguaje; de ahí, la importancia que juega la familia en el proceso de adquisición del lenguaje y en su proceso de socialización.

Por otro lado, tenemos el papel de las escuelas, quienes a través de su Diseño Curricular Nacional (DCN) plantean en su sistema educativo, en el área de comunicación, que los niños como sujetos sociales tienen una vocación natural a relacionarse con los demás y el mundo que los rodea, por tanto la comunicación, específicamente la oral, cumple un papel fundamental en el proceso de socialización. Por ese motivo, desde el nivel inicial se debe promover diferentes experiencias comunicativas reales, auténticas y útiles, donde los docentes deben facilitar este proceso con acciones de observación y experimentación directa de los objetos, personas, animales y todo lo que le rodea. De ninguna manera, los niños deben ser forzados a aprender a leer y escribir si no han desarrollado habilidades de la función simbólica, que hace alusión a la capacidad de "registrar, recordar y evocar mentalmente la imagen de los objetos sin verlos", sino han adquirido la madurez para ejercitar movimientos finos.

Otro aspecto a tomar en cuenta, es el desarrollo de la conciencia fonológica, aptitud que consiste en centrar la atención en los sonidos que componen el lenguaje. Es la toma de conciencia de que las palabras están formadas por partes, segmentos, que se corresponden con un determinado sonido.

Es la capacidad de ser consciente de las unidades en que puede dividirse el habla y desarrollar la habilidad de reconocerlas, identificarlas y manipularlas. Es la capacidad para discriminar auditivamente la secuencia de sonidos que forman sílabas y a su vez, palabras.
Todo esto, muchas veces queda tan solo en papel, puesto que en la realidad, en el campo de acción, en el campo clínico, se observa que cada vez llegan más niños a las consultas con dificultades fonológicas, niños que no logran discriminar auditivamente unas palabras de otras, niños que no desarrollan una función simbólica. En las aulas de inicial, cada vez se observa más, que éstas en su afán de que los niños ingresen a las mejores instituciones educativas y por ende aludan a su buena preparación en el inicial, buscan solo desarrollar el aprendizaje de letras, escritura y muchas veces los niños no están del todo maduros para estos aprendizajes y dejan de lado, lo vital del desarrollo del lenguaje y habilidades previas de otros aprendizajes.

Por lo tanto, se concluye que en el desarrollo del lenguaje, la familia y la escuela ejercen una influencia determinante, siendo la familia el primer entorno comunicativo y socializador, el cual debe generar un entorno rico en experiencias, hasta que haga su aparición la escuela en la vida del niño. Cuando el niño llegue a la escuela, debe procurar que su experiencia en ella se vaya ampliando y extendiendo a otros contextos, que además, van a ser de gran importancia en el desarrollo dellenguaje.

\section{CONCLUSIÓN}

Es importante resaltar que si realmente como educadores y padres se quiere hacer bien este trabajo, se debe potenciar la adquisición y el desarrollo del lenguaje en los niños. Hay que comenzar por buscar estrategias de prevención, elaborando un marco de trabajo en donde se desarrolle al máximo la adquisición de éste, evaluando en primer lugar, el desarrollo del lenguaje de los alumnos y si existe alguna señal que los lleve a intuir algún trastorno o déficit.

Desde este momento, se deben plantear objetivos concretos a desarrollar y recurrir a los especialistas si es necesario. A partir de ahí, todo será mucho más fácil y se empezará a obtener mejores resultados; en consecuencia, la evolución en el lenguaje de muchos niños irá desarrollándose cada vez más y con menos dificultades. 
En el compromiso con los niños, no se puede olvidar de un aspecto importante y vital como es la estimulación. Mediante la motivación y estimulación que reciba un niño en la etapa de infantil, puede avanzar grandes pasos en su desarrollo, en este caso, lingüístico. De esta manera, si las familias encuentran algún tipo de traba o dificultad durante su desarrollo evolutivo, deben acudir a especialistas y buscar fomentar y estimular con la guía indicada el lenguaje de sus hijos. Cuando las familias y la escuela no se percatan de las dificultades de los niños en lenguaje, estas terminan desembocando en un problema de mayor importancia. Por ello, la prevención, la motivación y la estimulación son unos de los principios de intervención educativa básicos para los niños.

\section{REFERENCIAS}

Acosta, M.; Ramos, Quintana, Espino (1996). La evaluación el lenguaje. Teoría y práctica del proceso de evaluación en la conducta lingüística infantil. Málaga: Aljibe.

Rondal (1993). El desarrollo del lenguaje. Barcelona: Ed. Médica y Técnica.
Gallego, O. y Fernández de Haro (2003). Enciclopedia de la Educación Infantil. Málaga: Aljibe.

Palacios, Marchesi y Cols (2002). Desarrollo psicológico y educación, Vol. I y III. Madrid: Alianza Editorial. 